\title{
Exploring Nanoemulsions for Prostate Cancer Therapy
}

\section{Authors}

Sushmita Srivastava, Md. Faheem Haider, Afroz Ahmad, Usama Ahmad, Muhammad Arif, Asad Ali

\section{Affiliation}

Faculty of Pharmacy, Integral University, Lucknow, India

\section{Key words}

protooncogenes, carcinoma, prostatectomy, nanomedicine, nanoemulsification, targeting, proliferation, cytotoxicity, apoptosis

received 23.02.2021

accepted 24.05.2021

published online $\quad 22.06 .2021$

Bibliography

Drug Res 2021; 71: 417-428

DOI 10.1055/a-1518-6606

ISSN 2194-9379

(c) 2021. Thieme. All rights reserved.

Georg Thieme Verlag KG, Rüdigerstraße 14,

70469 Stuttgart, Germany

\section{Correspondence}

Dr. Md. Faheem Haider

Assistant Professor

Faculty of Pharmacy

Integral University

Lucknow

226026

India

Tel.: + 91-7065237611

fhaider89@gmail.com

\section{ABSTRACT}

Prostate carcinoma is typical cancer. It is the second most common cancer globally. The estimated new cases in 2020 was 191930 and estimated deaths was 33330 . Age, family history, \& genetic factors are major factors that drive prostate cancer. Although, for treating metastatic disease, the major therapies available are radiation, bisphosphonate, and palliative chemotherapy. But the major drawback is therapy is disease-driven and later becomes metastatic and requires treatment. The ability to revolutionize cancer treatment by major targeting vehicles via the exploration of nanoemulsion suggests a potential for cancer treatment. The unique property of a biphasic liquid dosage form called nanoemulsion to reach leaky tumor vasculature is due to its nano-meter oil-droplet size of $20-200 \mathrm{~nm}$. Recent reporting on nanoemulsions disclose their embracing and lay alternative for re-purposing herbal and synthetic drugs and their combination especially for targeting prostate cancer formulating an obtainable nanomedicine. So, this article emphasizes the use of nanoemulsions incorporating therapeutic agents for successful and targeted delivery for prostate cancer.

\section{LIST OF ABBREVIATIONS}

$\begin{array}{ll}\text { AR } & \text { Androgen receptor } \\ \text { BSA } & \text { Bovineserum albumin } \\ \text { CASP7 } & \text { Caspase-7 } \\ \text { CDK1/CDC2 } & \text { Cyclin-dependent kinase 1/cell-division cycle 2 } \\ \text { CDK8 } & \text { cyclin-dependent kinase 8 } \\ \text { CSCs } & \text { cancer stem cells } \\ \text { ECCG } & \text { Epigallocatechin gallate } \\ \text { EPR } & \text { Enhanced permeability and retention effect } \\ \text { G2A } & \text { Glycine 2 to Alanine } \\ \text { HLB } & \text { Hydrophilic-Lipophilic balance } \\ \text { ICH } & \text { International Council for Harmonisation } \\ \text { IL-6 } & \text { Interleukin-6 }\end{array}$

$\begin{array}{ll}\text { LNEs } & \text { Lipid nanoemulsions } \\ \text { Mc-1 } & \text { melanocortin 1 } \\ \text { MDK } & \text { Midkine gene } \\ \text { MDR } & \text { multidrug resistance } \\ \text { mTOR } & \text { mammalian target of rapamycin } \\ \text { NF-KB } & \text { Nuclear factor kappa light chain enhancer of } \\ & \begin{array}{l}\text { activated B cells } \\ \text { nuclear erythroid 2-related factor/antioxidant } \\ \text { Nrf2/ARE }\end{array} \\ \text { p53 } & \begin{array}{l}\text { response element } \\ \text { phosphoprotein-53 }\end{array} \\ \text { P-GP } & \text { para-glycoprotein } \\ \text { PI3K/AKT } & \text { phosphatidylinositol 3- kinase/protein kinase B) } \\ \text { PLA2 } & \text { Phospholipase A2 } \\ \text { PLGA } & \text { Poly-Lactic co-Glycolic-Acid }\end{array}$




\begin{tabular}{|c|c|}
\hline PLK1 & polo-like kinase \\
\hline PTTG1 & Pituitary tumor transforming gene 1 \\
\hline RAS/MAPK & $\begin{array}{l}\text { Rapidly accelerated Fibrosarcoma/mitogen- } \\
\text { activated protein kinase }\end{array}$ \\
\hline RGD & Arginine-Glycine-Aspartic \\
\hline ROS & Reactive oxygen species \\
\hline STAT3 & $\begin{array}{l}\text { Signal transducer and activator of transcrip- } \\
\text { tion } 3 .\end{array}$ \\
\hline TICs & tumor-initiating cells \\
\hline Wnt & Wingless-related integration site \\
\hline ZVAD-FMK & $\begin{array}{l}\text { carbobenzoxy-valyl-alanyl-aspartyl-[O- } \\
\text { methyl]-fluromethylketone }\end{array}$ \\
\hline
\end{tabular}

\section{Introduction}

The normal growth of cells and malignancy are two different functional alternatives of an organism. The elemental characteristic of normal cells is their division at a particular rate as they have a restricted life-span. Both in vivo and in vitro, normal cells have a limited number of division cycles.

Malignant cell modification appears due to a set of cellular genes called oncogenes by the effect of carcinogens; hormonal factors such as sexual hormones; physical factors thus included in the evolution of neoplasia. Changes in extension rates occur due to the network's functional dysregulation in which tumor suppressor genes (TSCs) and protooncogenes are interconnected. Consequently, by overexpression, protooncogenes are transformed into oncogenes with malignant capacity while TSGs, by loss of their function, are involved in malignant transformation [1]. Cancer is a leading cause of morbidity and mortality across the globe (-Fig. 1) [2]. The substantial amount of incidences and deaths by cancer is allotted by lung, breast, prostate, colorectum, stomach, and liver ( data outlined by the International Agency for Research on Cancer with particular bodies such as National Cancer Institute (NCI), American Cancer Society, National Center for Health Statistics (NCHS), Centers for Disease Control and Prevention's (CDC's), North American Association of Central Cancer Registries and the International Association of Cancer Registries. In 2018, 9.6 million deaths worldwide occurred due to cancer, and in the next few decades, new cases are projected to grow above $70 \%$. In 2018, about 18.1 million new cases were diagnosed worldwide [3-5]. In 2019, about 1762452 new cases were alone accounted for the U.S, almost equal to 4800 cases per day [6]. To this conclusion, a major part of deaths related to cancer can be prevented through primary prevention by targeted preventive units and screening programs are crucial tools to detect and attenuate adaptable danger personally in a convenient way [79]. Moreover, patients with cancer could display longer survival rates at the secondary level of prevention disease management would adjust treatment functions specific to a personal patient profile [10,11]. - Figure 1 is based on data published in 2019 [2].

Prostate cancer is second to lung cancer as the primary cause of death and in past years its research interest has increased, so this article emphasizes prostate cancer treatment by use of nanotechnology-based approaches, specifically with nanoemulsion by repurposing herbal and synthetic drugs and their combination tar-

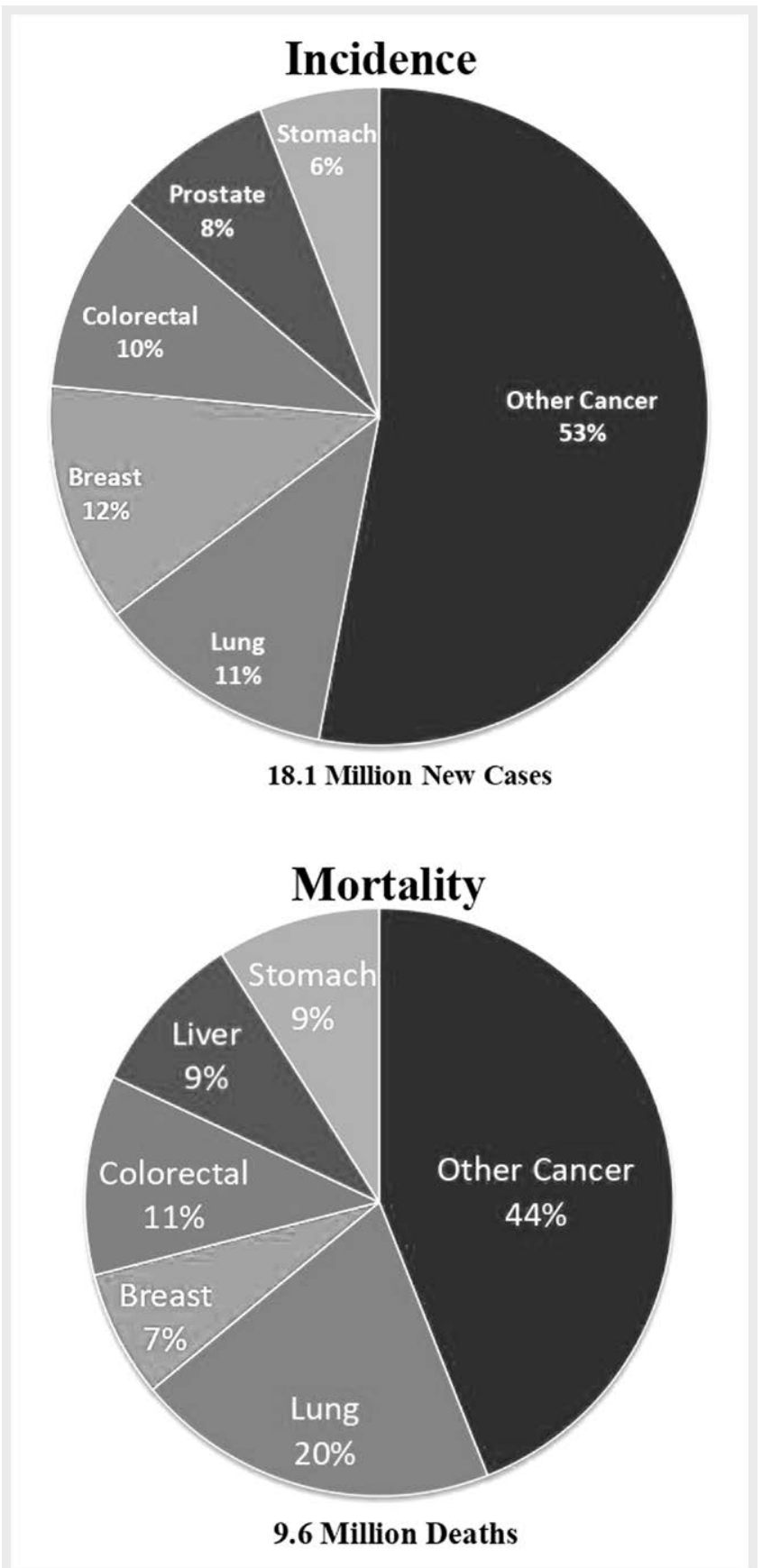

Fig 1 Global cancer statistics presenting the most prevailing and mortality of different types of cancer.

geted to prostate cancer for creating and formulating approachable and attainable nanomedicine.

Carcinoma of the prostate or cancer of the prostate is known as prostate cancer [12]. It is the most typical cancer in men in 84 countries [13]. In men, it is the fifth major cause of death. It is the second most common cancer globally [14]. It was tested in 1.2 million and lead to 359000 deaths in 2018 [15]. In today's world, the rate is perpetually increasing [16]. It is found in every one out of six American men and is most likely to occur during his life period [17]. 
There is a variation in rate in different countries, it is most common in New Zealand, North America, Australia, and Europe, and very less common in East and South Asia [18]. It is most likely seen in black men and so less likely seen in Asian men with white in between two $[19,20]$. It is the third type of leading cancer in Canadian men, with an estimated 4000 deaths out of 21600 detected [21]. In Europe, after lung cancer, prostate cancer is the most primeroot of death. Yearly 10000 deaths out of 35000 being detected [22]. Until 2040, 2293818 new cases are estimated with a small variation in mortality will be observed in $1.05 \%$ [23]. It is calculated that mortality with 379005 deaths worldwide. The lowest incidence rate will be registered in Europe ( $+58.3 \%$ ) followed by Asia $(+116.7 \%)$ while the highest in Africa (+124.4\%) [23]. More often, patients are generally asymptomatic, until their disease becomes metastatic. Indeed, many treatments are available, but they are quite expensive and associated with lots of side-effects. Although, prostatectomy or radiation therapy is most effective for the earlystage treatment of localized prostate cancer, treatment of metastatic disease cancer is often driven by developing a biological mechanism of drug resistance, as prostate cancer arises by the androgen-driven disease [24], the major therapy considered for patients suffering from metastatic or advanced prostate carcinoma is ADT or androgen deprivation therapy to particularly target androgen- receptor axis [25]. Although ADT is effective initially, resistance is still developed in many patients and androgen-independent or develop castration resistance prostate cancer [26, 27]. The etiology of prostate cancer requires an extensive study and remains largely unknown compared to other common types of cancers ( $>$ Fig. 2). Well-known risk factors for advanced prostate cancer are increasing age, family history, and several genetic factors [28-30].

The cells of the prostate are dependent on cell-signaling pathways for their optimal growth, nutrition, and development. However, disturbances in their mechanism lead to the growth of cancerous tissue transformations in the epithelium of the prostate which require treatment strategies ( $\triangleright$ Fig. 2 ). So, [31] reviewed the molecular and functional evidence that inhibiting some of the common pathways involved in a progression such as PI3K/AKT; RAS/

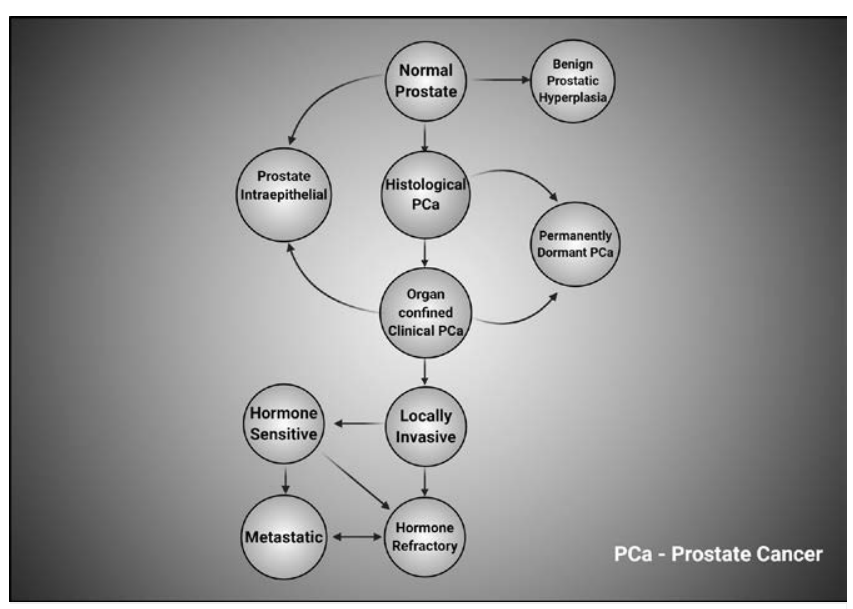

- Fig 2 Global cancer statistics presenting the most prevailing and mortality of different types of cancer.
MAPK, and STAT3 signaling pathways mediated by growth factor driven receptor tyrosinekinase (RTK) e. g., epidermal growth factor receptor (EGFR) or cytokine (e.g.IL-6). Signaling potentiates the self-renewal capacity of prostate cancer stem cells and their development. In this article, the drugs enlisted below are a major inhibitor of some of these signaling pathways thereby resulting in apoptosis and death of neoplastic transformations.

There are various types of therapies obtainable for prostate cancer, such as active surveillance, radiation therapy, hormone therapy, radiopharmaceutical therapy, hormone therapy, immunotherapy, bisphosphonate therapy, chemotherapy [32], the risk-benefit relationship should be clearly understood before any sort of treatment after being diagnosed. Patients with unresectable and metastatic cancer may benefit from (palliative) chemotherapy. Although, several studies support curcumin as an anti-cancer drug, yet clinical use is highly restricted because of its low bioavailability and poor absorption of tissue in numerous studies [33, 34]. Different proposals have been accepted to resolve this issue, such as the evolution of delivery systems (for example, nanoparticles, nanoemulsions, and liposomes), etc [35-38].

Since they have unique chemical and physical properties, nanocarrier-based delivery systems are favorable aspirants for the growth of systematic before-time diagnosis and therapeutic tools, frequently incorporated in a theranostic platform to enhance cancerous patient's prospects. A huge diversity of nanostructured materials, such as nanoparticles, nanoemulsions, nanoencapsulation, quantum dots, polymeric nanoparticles, micelles, liposomes, inorganic (titanium, iron- oxide, silver, and gold), ceramic-based carriers, carbon nanotubes, nano-shells, and dendrimers, are nowadays examined as the latest implementation in various anti-cancer treatment [39]. Nanomedicine-based approaches have attracted the attention of researchers due to their tumor-targeting ability [40]. These delivery systems provide Sustained-release action to target cells by an anticancer drug, and normal cells are protected by unnecessary exposure. Through nanomedicine based approaches, drug-related toxicity and therapeutic output are increased [41]. The ability of transferrin-mediated curcumin of solid-lipid nanoparticlesintensifies the anti-cancer effect in breast cancer cells [42]. Polymeric-based drug conjugate (Polyglutamic acid-RGD peptide) targets tumor tissue utilizing enhanced permeability and permeability effects (EPR) effects serving increased anti-tumor activity with decreased toxicity when compared to free paclitaxel-treated mice [43] with amplified antiangiogenic effect. PEGylated PLGA based nanoparticle attached with RGD peptide-paclitaxel loaded nanoparticle has been outlined for targeting of tumorepithelium [44].

A fascinating and vital evolution in the exploration in the use of nanoemulsion is for targeted drug delivery to cancer as they can be easily targeted to tumor tissue because of their nano-meter oil-droplet size using targeted molecules on the surface of nanoemulsions. Recent studies also designate that they have broad attentiveness as colloidal carriers for the selectedcarriage of many anti-cancer drugs [45-48] and diagnostic agents [49, 50]. Nano-emulsification serves as aninstrument to improve the drug solubility, oral bioavailability of lipophilic compounds, and absorption via lymphatic system with bypassing first passing metabolism and membrane transport [51]. Over many conventional drug delivery systems, available nanoemulsion possesses several advantages: reduced inter-subject differenc- 
es, rapid onset of action, and high solubilization capacity [52]. Here is the example of the study conducted by the researchers in which the formation of nanoemulsion increases the encapsulation, which leads to cancer cell apoptosis. Many studies reveal that tumor cells articulatingCSCs markers mainly CD133 and CD4 are correlated with drug resistance and quicken after therapy [53]. Due to the up-regulation of drug efflux transporters, additional structured reactions to DNA damage and repair processes, and anti-apoptotic mechanisms, there is a drug resistance in CSCs [54]. The populations of fast-growing cancer cells are targeted in prostate cancer therapy but exclude subpopulations like CSCs or TICs which is the major problem in therapy. Also, to assess anti-cancer agent's anti-prostate cancer development restricts cell lines with high passage numbers to pre-clinical studies that end with epigenomic or genomic features with very less or no pairing with original cancer [55]. From prostate cancer patient a cell line PPT2 with very low passage number and through this way stem-like properties and immaturity are kept by the team of researchers who conducted this study. Genes of PPT2 cells are connected with anti-apoptotic signaling and drug resistance to a drug being an impeccable model for CSC targeted therapy studies [56]. For therapy of prostate carcinoma one drug that is often used is a paclitaxel-pro drug, Abraxane. It is designed to accelerate its solubility with human serum albumin-bound nanoparticle formation. In MDR cancer cells, Paclitaxel exhibits complications [54]. SBT-1214, is a new generation taxoidthatis potent in case of drug resistance, this taxoid is interfusedwithdocosahexaenoic acid (DHA), a natural polyunsaturated fatty acid (PUFA), with high empathy towards its main bloodstream transporter (human serum albumin) that help direct toxicity to cancer. The Association of DHA with paclitaxel leads to a weak decrease in P-GP and ABC transporters [57]. The nanoemulsion formation of DHA-SBT-1214 in this study holds phospholipids and fish oils. The encapsulation of the drug is increased due to the association of the drug with fish oil. It is told that nanoemulsion formed will function on CSC initiated PPT2 cell line making utilization of EPR effect and ensue in apoptosis of cancer cell [54]. With the use of patient procured CSC enriched PPT2 cells, the formation of drugs that target cells enhanced for tumor initiation can be done. Association of DHA with SBT-1214 increases the blood circulation time of the drug. Encapsulating the associated hydrophobic drug in nanoemulsion formation resulted in effective delivery; Thus, the drug circulation time is enhanced by surface moderation with PEG which accelerates accumulation due to the EPR effect. The nanoemulsionformation can deliver its payload more adeptly as compared to drug solution which can be seen by successful cellular uptake [54].

\section{Nanoemulsion}

The important framework that differentiates a nanoemulsion $(\mathrm{d}<200 \mathrm{~nm})$ from a conventional emulsion $(\mathrm{d}>200 \mathrm{~nm})$ is the proportions of the droplet. As a result, conventional emulsions always have a tendency to degrade over time. $[58,59]$. Because of the small particle size, nanoemulsions are much more resistant to gravitational separation and aggregation than conventional emulsions $[60,61]$. Nanoemulsions (NE) have a kinetic stability, microemulsions, on the other hand, are thermodynamically stable. In terms of formulation, a microemulsion requires a higher surfactant-tooil ratio (SOR) than a nanoemulsion. As a result, the particle size of microemulsion is smaller than that of nanoemulsion. For particle size distribution, a single narrow peak is observed in microemulsion, whereas a single or multiple narrow or broad peaks are observed in nanoemulsion. Particles in nanoemulsions are mostly spherical, whereas particles in microemulsions can be spherical or non-spherical [62]. For molecules with low water solubility, nanoemulsion is colloidal dispersion that can be used as a drug vehicle formed with safe grade excipients $[62,63]$. It is a heterogeneous dispersion of nano-meter droplets in another liquid which makes them a carrier with high stability and solubility [64]. There are three types of nanoemulsion which are given as under:

(1) Oil in water nanoemulsion in which oil droplets are dispersed in water.

(2) Water in oil nanoemulsion in which water droplets are dispersed in oil.

(3) Bi-continuous phase.

They mainly contain water, surfactant, and oil ( $\mathbf{F i g}$. 3). The two immiscible phases are separated by surfactants which reduce the interfacial tension between two immiscible phases [65]. For the preparation of oil in water nanoemulsion, surfactants with an HLB value of 8-18 are used whereas for preparation of water in oil-based nanoemulsion the preferred value of HLB is from 3-6 [66].

The absolute emulsifying agent should be rapidly absorbed, reduce the interfacial tension as electrostatic or stearic interaction stabilizes the surface. Surfactants such as amphiphilic proteins like caseinate or phospholipids such as soya lecithin; modified starch in the category of polysaccharide or polymers such as polyethylene glycol [67] and non-ionic surfactants like sorbitan fatty acids ester such as Spans can also be utilized [68].

The oily phase acts as an organic phase and a carrier for active ingredients. The proper selection of the oily phase is a very crucial part of the manufacturing nanoemulsions as it affects the facilitation and solubility of active moieties of nanoemulsion for the preferred cause. Especially in oil in water nanoemulsions, the selection of the oily phase is an important part as it affects various other components in the formulation [69].

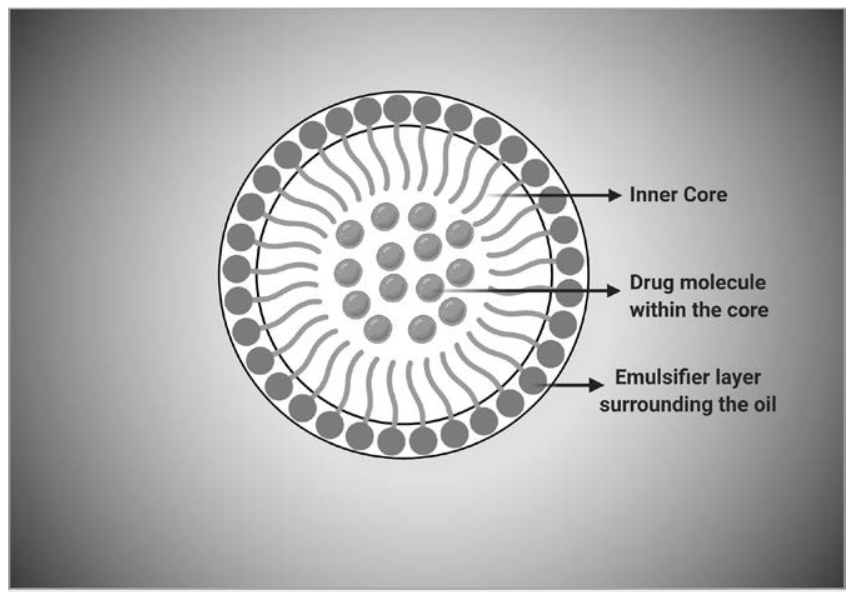

Fig 3 Global cancer statistics presenting the most prevailing and mortality of different types of cancer. 
There are various solvents employed for the preparation of the nanoemulsion. Various characteristics of the aqueous phase such as interfacial tension, viscosity, density, and structural properties of the solution of surfactant increase desired curvature and critical micelle concentration [70].

The two phases of nanoemulsion production are mixed and heated phases with optimum temperature and agitation to achieve a homogeneous mixture. To achieve optimum particle size a process of shear force homogenization is achieved. At last, the structure will have a layerof emulsifier separating the lipophilic interior from the aqueous phase. To stabilize the formulation this unique layer acts as a barrier and shows repulsive forces depending on the emulsifier [71].

Nanoemulsion preparation can be divided into two zones which are high energy and low energy methods ( $\mathbf{F i g}$. 4). High energy requires a power input of $10^{7}$ to $10^{9} \mathrm{~W} / \mathrm{kg}$ and low energy methods require power input of $10^{3}$ to $10^{5} \mathrm{~W} / \mathrm{kg}$ [72]. High shear methods utilize microfluidizers, ultrasonicators, and homogenizers [73]. For perfectly-being scaled up on one side, on the other they reflect a limitation for heat-sensitive drugs. Due to this, low energy and temperature methods must be used like phase inversion methods and self-emulsification phase transition [74].

There are many advantages of nanoemulsion as a structured nano-carrier:-

- Nanoemulsion being structured lipids are manufactured and utilized for increasing the in vivo circulation time [75].

- The capacity of nanoemulsion to solubilize a huge number of both hydrophilic and hydrophobic drugs and their capacity to safeguard the drugs from hydrolysis and enzymatic degradation makes nanoemulsion an ideal platform for the delivery of parentals [76].

- Moreover, they can be used for image-guided delivery of a drug by making use of targeting and imaging components [77].

- They are also being tested extensively for their ability in applications in ophthalmic [78]; pulmonary [79]; and transdermal [80].

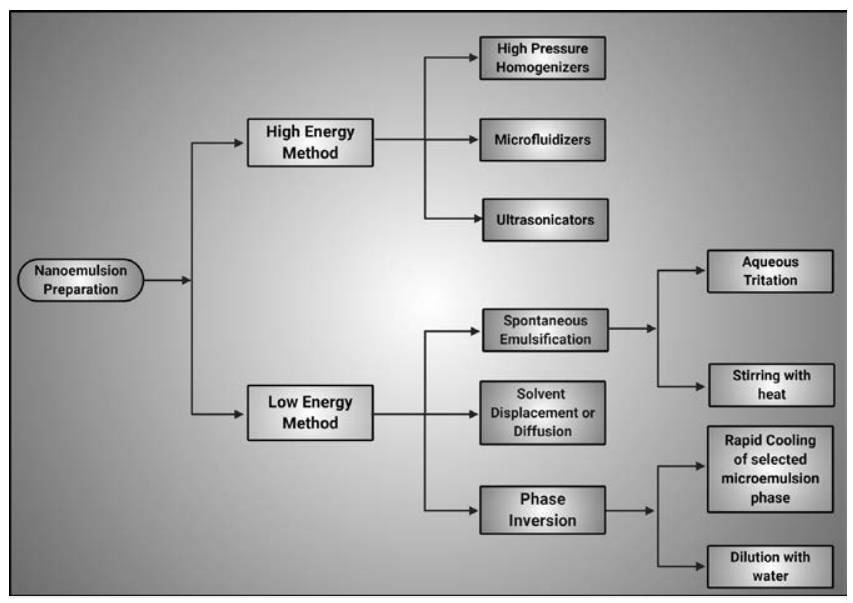

- Fig 4 Global cancer statistics presenting the most prevailing and mortality of different types of cancer.
- It can be developed for several formulations such as liquids, sprays, creams, and foams [81].

- They have a larger surface area and wider absorption [82].

Disadvantages:-

- Bioactive components typically have very low bioavailability; however, if their absorption by the human body is significantly increased by incorporation into a nanoemulsion, they may exhibit toxic effects that cannot be predicted using data obtained on the same material in macroscopic form [62].

- Nanoemulsion particles may be able to bind to cellular membrane receptors, disrupting the cell's normal metabolism and function [83].

- The combination of small size, high surface area and high surface energy in nanoemulsion may effect in biological systems that are not predictable from the bulk form of the same materials [84].

- The higher usage of surfactants in nanoemulsions compared to conventional emulsions may have some adverse health effects [62].

\section{Nanoemulsion based Delivery of Various Therapeutic Agents having Activity against Prostate Cancer}

\section{Natural Drugs}

Catechin

Catechins because of their instability, in-vivo bioavailability remained low [85-87]. Thus, with the help of the preparation of micro or nanoemulsion, bio-active moiety such as catechin can be encapsulated. A study has been displayed by [88],who prepared catechin nanoemulsion constituting cholesterol, phytosterol, glycerol, and water and the average particle size was found to be $300 \mathrm{~nm}$ by DLS analysis. Here is a study conducted by [89], in which a nanoemulsion is composed of catechin extract, $0.5 \%$ lecithin, $5 \%$ tween 80 , and $94.5 \%$ deionized water was prepared and mean particle size being $11.45 \mathrm{~nm}$, polydispersity index 0.27 , encapsulation efficiency 88.1 and zeta potential $-66.3 \mathrm{mV}$. High stability of catechin nanoemulsion was shown at a period of 120 days at $4{ }^{\circ} \mathrm{C}$. Both catechin and catechin extract could inhibit prostate cancer cell PC-3 proliferation with $\mathrm{IC}_{50}$ being $15.4 \mu \mathrm{g} / \mathrm{mL}$ and $8.5 \mu \mathrm{g} / \mathrm{mL}$ respectively stating that the nanoemulsion possessed a more pronounced inhibition effect toward the growth of PC-3 tumor cells ( $\triangleright$ Table 1 ).

The anti-cancer activities of EGCG are relevant to be pushed by targeting multiple pathways that are mainly involved in cancer progression, such as mitogen-activated proteinkinase (MAPK); nuclear factor kappa-light-chain-enhancer of activated B cells (NF-кB); the epidermal growth factor receptor (EGFR) and insulin-likegrowth factor receptor (IGF-1) mediated pathways [90].

\section{Curcumin}

Recent studies showed that curcumin encapsulated in polymeric nanoparticles could improve the therapeutic efficacy as compared to free curcumin as a result of increased solubility in aqueous media [91-93]. Moreover, different from free curcumin, curcumin nanoemulsions induced more PC -3 cells arrested in the $G_{2} / M$ phase, which 


\begin{tabular}{|c|c|c|c|c|c|c|c|c|c|c|c|}
\hline 亗 & $\stackrel{\overline{\mathscr{\infty}}}{\mathscr{\Phi}}$ & 㤀 & $\stackrel{\check{g}}{\varrho}$ & $\stackrel{\infty}{\varrho}$ & פ & $\stackrel{\infty}{\stackrel{\infty}{\underline{O}}}$ & 焉 & $\underline{\underline{\Xi}}$ & $\underset{\Xi}{\Xi}$ & 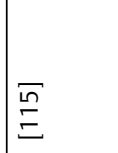 & $\bar{E}$ \\
\hline 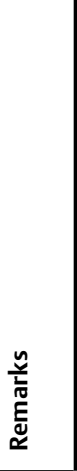 & 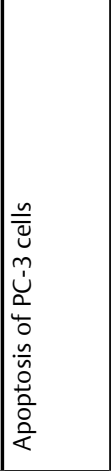 & 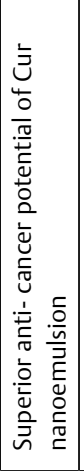 & 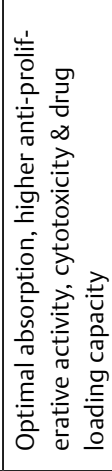 & 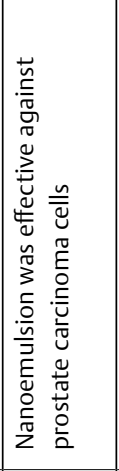 & 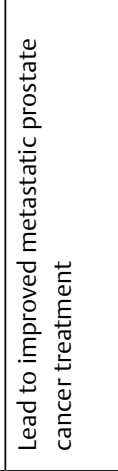 & 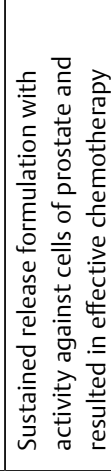 & 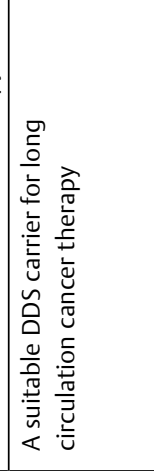 & 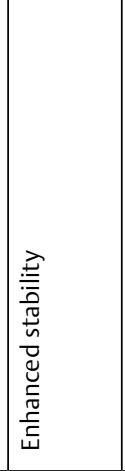 & 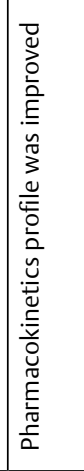 & 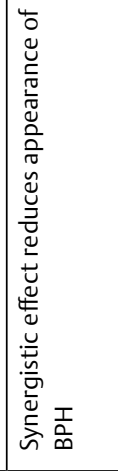 & 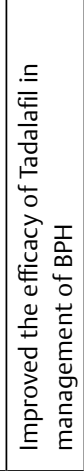 \\
\hline 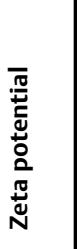 & 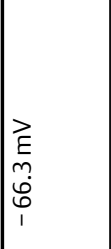 & 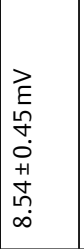 & 1 & 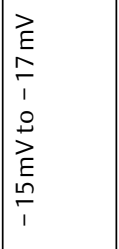 & 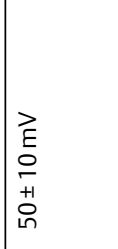 & 1 & 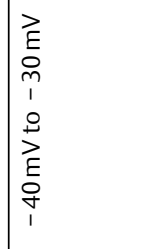 & 1 & $\begin{array}{l}\overrightarrow{\mathrm{E}} \\
\infty \\
\infty \\
\stackrel{\hat{N}}{1} \\
\overrightarrow{1}\end{array}$ & 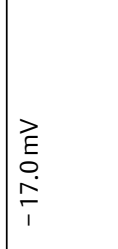 & 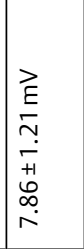 \\
\hline 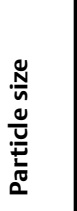 & 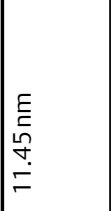 & 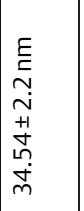 & 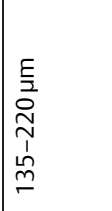 & 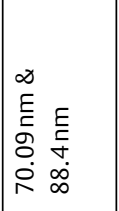 & 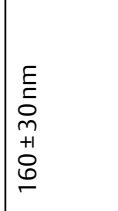 & 1 & $\begin{array}{l}E \\
\text { E } \\
\text { in }\end{array}$ & 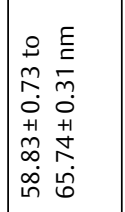 & $\begin{array}{l}E \\
\underline{E} \\
\stackrel{E}{\mathrm{n}} \\
\mathrm{v}\end{array}$ & \begin{tabular}{|l}
$E$ \\
E \\
0 \\
0 \\
1 \\
$\dot{q}$
\end{tabular} & $\begin{array}{l}E \\
E \\
D \\
D \\
\infty \\
\infty \\
+1 \\
+\infty \\
\infty \\
\dot{D} \\
\sim\end{array}$ \\
\hline 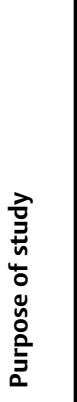 & 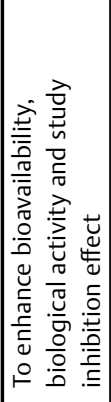 & 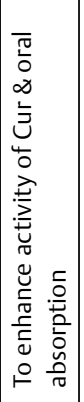 & 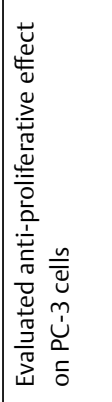 & 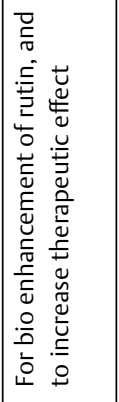 & 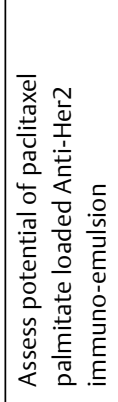 & 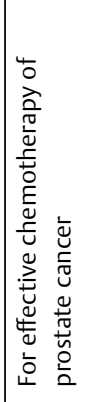 & 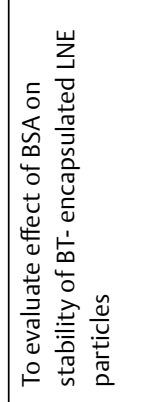 & 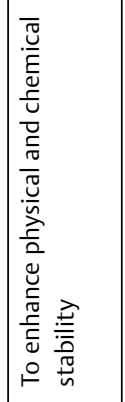 & 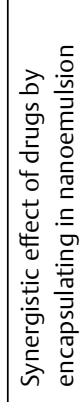 & 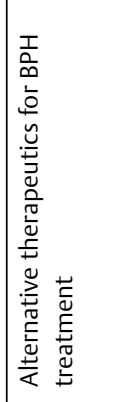 & 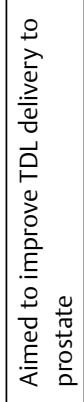 \\
\hline 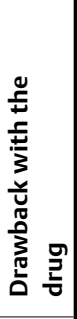 & 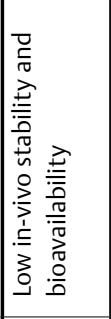 & 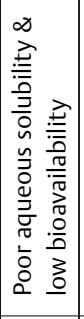 & 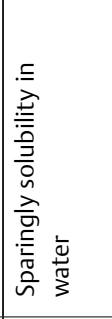 & 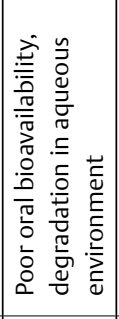 & 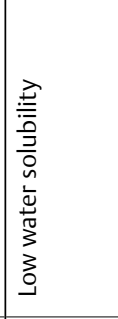 & 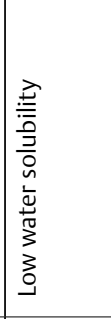 & 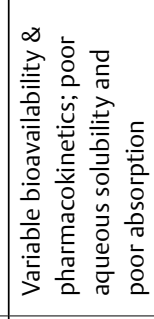 & 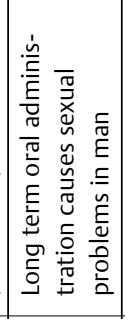 & 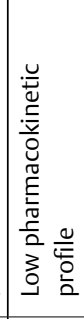 & 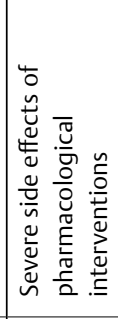 & 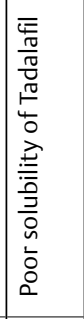 \\
\hline 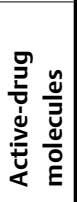 & 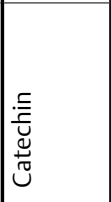 & 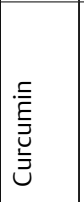 & 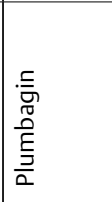 & $\begin{array}{l}\text { 言 } \\
\overline{\underline{\alpha}}\end{array}$ & 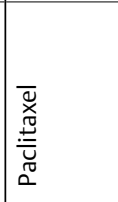 & 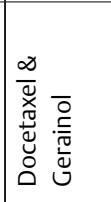 & 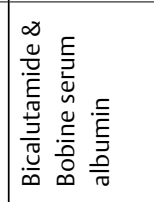 & 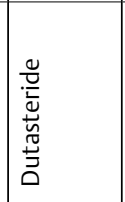 & 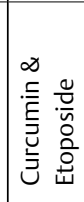 & 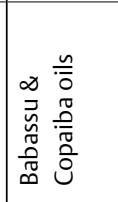 & 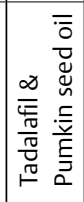 \\
\hline 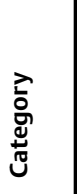 & $\begin{array}{l}\frac{9}{3} \\
\frac{\underline{2}}{0} \\
\frac{\pi}{0} \\
\frac{0}{0} \\
\frac{0}{1}\end{array}$ & 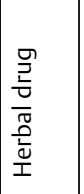 & 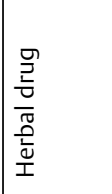 & 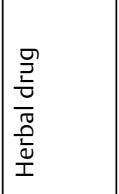 & $\begin{array}{l}\frac{9}{2} \\
\frac{2}{0} \\
\frac{0}{0} \\
\frac{0}{2} \\
\text { I }\end{array}$ & 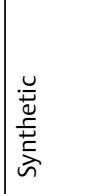 & 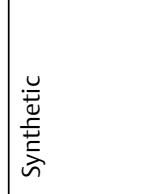 & 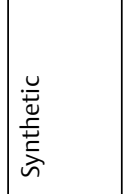 & 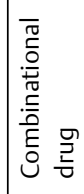 & 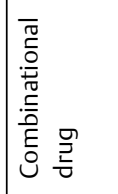 & 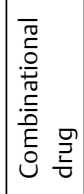 \\
\hline$\sum_{i}^{0}$ & - & $\sim$ & $m$ & $\sigma$ & in & 0 & $r$ & $\infty$ & $a$ & $\circ$ & $=$ \\
\hline
\end{tabular}


might be due to the slow release of the nanoemulsion [93]. In [94], their study concluded that nanoemulsions could be loaded efficiently with curcumin and therefore increase the solubilization of the drug encapsulated within. Nanoemulsion could increase cellular uptake, cellular cytotoxicity, cell cycle arrest, and apoptosis against prostate cancer cells. Curcumin encapsulated within nanoemulsion was released slowly into the cells thereby resulting in prolonged cytotoxicity and also cell-cycle arrest in PC-3 cells ( $\triangleright$ Table 1). Also, in-situ single-pass perfusion studiesshowed a higher effective permeability coefficient for Curcumin nanoemulsion than that of free curcumin.

Through the down-regulation of androgen receptor and epidermal growth factor receptor, curcumin targets prostate cancer metastasis development, and proliferation and also by the induction of cell-cycle arrest. Through the inhibition of pro-inflammatory mediators and the NF-кBsignaling pathway, it mediates inflammatory response. The results also reveal that the molecule potency towards induction of pro-apoptotic proteins and downregulates the antiapoptotic counterparts [95].

\section{Plumbagin}

Plumbagin loaded oleic acid-based nanoemulsion was prepared, using high-pressure homogenization of oleic acid emulsion with polysorbate 80 as an emulsifying agent. The plumbagin-loaded nanoemulsion ( $135 \mathrm{~nm}$ of zeta-potential; $10 \% \mathrm{w} / \mathrm{w}$ ) oleic acid, $3.5 \%$ $\mathrm{w} / \mathrm{w}$ polysorbate 80 ) was selected for proper size distribution over time, and polydispersity was selected for further studies of drug release, stability in simulated physiological fluids, and in-vitro cytotoxicity against PC-3 cells. The plumbagin loaded nanoemulsion showed good retention of nano-particulate size, after dispersion in water or media simulating physiological environment. Moreover, the exponential release of plumbagin from nanoemulsionwith half-lives had permit optimal absorption of plumbagin from the gastrointestinal tract is shown by drug-release studies. As compared to free plumbagin, plumbagin encapsulated nanoemulsion displayed higher anti-proliferative activity on PTEN-P2 cells ( $\triangleright$ Table $\mathbf{1}$ ) [96].

Plumbagin exhibits anti-cancer effects via interaction with multiple targets and modulation of various molecular signaling pathways including CDK1/CDC2, cyclin B1, cyclin D1, AMPK, NF-кB, p53, p21, Cip1/Waf1, p27Kip1, Nrf2/ARE, mTOR/AKT/PI3K \&Wnt [97].

\section{Rutin}

The percentage of cell viability and cell morphology by rutinnanoemulsion significantly reduces cell viability of prostate cancer cell line PC-3 in a dose-dependent manner [98]. In this, they have also shown that rutinnanoemulsion induces intracellular ROS generation thus provoking cell death. The bioactive encapsulated in rutin nanoemulsion system was found to be more effective against prostate cancer cell line at a very low concentration as compared to the free or purified form of rutin thus inducing apoptosis ( $\triangleright$ Table 1 ). The in-vivo anticancer activity and bio-distribution studieson animal models of cancer are suitable to expand and explore the anticancer potential of rutin nanoemulsion. As compared to pure drug suspension the in-vitro drug release studies from rutinnanoemulsion were significantly higher $(p<0.05)$.
Through fluorescent microscopic analysis and intracellular ROS generation explained that significant ROS induction might lead to manipulating apoptosis pathway.

\section{Paclitaxel Palmitate}

Anti- HER2 cationic immune-emulsion for treatment of prostate cancer was prepared [99]. Taxanes such as paclitaxel exhibit a wide variety of antitumor activity, its therapeutic application are restricted due to poor solubility. The objective of their study was to assess the efficiency of paclitaxel palmitate loaded anti-HER2 immunoemulsion covalently linked to an anti-HER2 monoclonal antibody (Herceptin) in an in-vivo pharmacologic model of metastatic prostate cancer that overexpresses HER2 receptor. It was noted that cationic emulsion and immune-emulsion did not activate complement compared with commercial and paclitaxel palmitate hydroalcoholic formulations. Moreover, $10 \mathrm{mg} / \mathrm{kg}$ of paclitaxel palmitate loaded immune-emulsion once weekly over 3 weeks inhibits tumor growth in severe combined immunodeficient mice much more than the cationic emulsion $(P<0.05)$ and the paclitaxel-palmitate formulation $(P<0.01)$. Histopathologic studies were in favor of immune-emulsion. They concluded that tumor growth was not fully inhibited but actual results are encouraging and lead to an improved therapeutic strategy of metastatic prostate cancer treatment ( $\triangleright$ Table 1) [100], suggested paclitaxel a widely used mechanism of action is connected to its potential to arrest cells in mitosis and intrinsic pathway induction. In LNCaP cells, however PTTC1 downregulation prevents mitotic entry and subsequently inhibits mitosis-associated paclitaxel-induced apoptosis. They also identified a role for Mc-1 protein in preventing apoptosis during mitosis in PC-3 cells as alternatively PTTG1 and Mcl-1 silencing enhances mitosis linked apoptosis after paclitaxel treatment.

\section{Synthetic drugs}

\section{Bicalutamide}

Bicalutamide is a non-steroidal, anti-androgen used for the treatment of prostate cancer $[101,102]$. Although it has high in-vitro potency, after oral administration, its absolute bioavailability and pharmacokinetics are highly variable due to poor absorption [103]. For the development of a stable drug carrier for bicalutamide(BT), LNEs (Lipid nano-emulsions) were prepared from a lipid mixture of soyabean oil, phosphatidylcholine, sodium palmitate, and sucrose palmitate(SP) [104]. These Lipid Nanoemulsions had a mean particle size of approximately $50 \mathrm{~nm}$ and zeta potential of -40 to $30 \mathrm{mV}$ and their stability was assessed in saline solution and bovine serum by dynamic light scattering method. The droplet size of LNEs hardly increased even after 72 hours placed in bovine serum suggesting bovine serum albumin suppressed their coalescence. The intrinsic fluorescence of BSA was blue-shifted in presence of LNEs. Moreover, zeta potential values of all LNEs increased to around $-20 \mathrm{mV}$ according to an increase in BSA concentration. These results stated that BSA interacted with LNE particles and acts as a suitable drug delivery system for bicalutamide and its significant role in cancer therapeutics ( Table 1).

By demonstrating the exact pathways through which bicalutamide induces its anti-apoptotic effect would help to advance its clinical application. 
To identify a specific pathway of action for bicalutamide, [105] pre-treated PC-3 and PWR-1E cells with some specific inhibitors such as calpain 2 inhibitor(caspase-independent pathways and caspase-dependent (zVAD-FMK). Bicalutamide via caspase and calpain independent mechanism induced apoptosis in androgen-dependent PWR-1E cells. This moiety also induced apoptosis by some underlying phenomena that are gradually inhibited by pan-caspase inhibition but were somewhat calpain development.

\section{Dutasteride}

Dutasteride, a $5 \alpha$ - reductase inhibitor has been recommended for the treatment of BPH upon oral administration. However, its longterm use can cause sexual problems in men so to enhance physical and chemical stability and remove toxicity [106] formulated nanoemulsion of dutasteride by the aqueous-titration method. Lowsurfactant containing nanoemulsion was taken for further study to decrease the toxicity problems. A stability study was performed according to $\mathrm{ICH}$ guidelines and the formulation was found to be stable. The droplet size, viscosity, and RI of optimized nanoemulsion show that there were no changes in 3 months of storage stating the nanoemulsion were found to be physically stable. There is slower degradation of dutasteride in nanoemulsion indicating chemical stability ( $\triangleright$ Table 1 ). The shelf-life was found to be 2.18 years at room temperature [107] found out that dutasteride kills PCa cells in vitro, they used the most common prostate cancer cell line LNCaP. Moreover, it reduced viability and proliferation disrupted genes and cellular pathways that are involved in metabolic cell cycle and apoptotic responses besides those that are expected in androgen-signaling pathways. Activation of genes in the FaSL/ tumor necrosis factor-alpha (TNF- $\alpha$ ) apoptotic and cell-survival pathways correlating with growth and survival effects are revealed by microchip gene array expression analysis. Candidate genes such as PLA2, G2A, CDK8, CASP7, MDK, and NKX3.1 expression level change seen by microarray analysis is confirmed by a real-time polymerase chain reaction.

\section{Docetaxel}

A docetaxel nanoemulsion for effective chemotherapy of prostate cancer [108]. DTX-Ger-Nanoemulsionformulation has been designed and developed with desired size and size potential. Pre-formulation studies conducted revealed that the API and excipients were authentic and of standard grade. The formulation has narrow size distribution and spherical shape which is suitable for I.V administration. In the end, it was also concluded that the formulation is sustained release. From the stability studies, it was shown that the formulation is stable at $4{ }^{\circ} \mathrm{C}$ and $25^{\circ} \mathrm{C}$ for 3 months. Cell uptake studies revealed that the formulation is extensively taken up by cancerous cells so it can be said that the efflux mechanism of the cell is inhibited and formulation is capable of delivering its effect. From in-vitro studies, it is revealed that the formulation is active against cancerous cells. Haemolysis study revealed that the use of Geraniol oil is unsafe for I.V administration but on the other hand shows improved anti-cancer activity ( $\triangleright$ Table 1$)$. Therefore, geraniol should be used with caution for I.V administration.

In the study conducted by [109], the apoptotic inhibitory effect of Doc on androgen-independent or androgen-dependent prostate cancer cells was tested and then they tried to demonstrate the regulation of phosphoinositide 3- kinase (PI3K/Akt) signaling pathway in Dox-induced apoptosis. Their studies demonstrated that therapy of three prostate cancer cell lines, with Dox, decreases the level of phosphor-Akt. It has already been reported that the development of Doc resistance is linked to activation of AR [110] which is relevant with the data which thereby confirmed the originality of their data.

\section{Combination drugs}

Pumpkin seed oil and Tadalafil

FDA has approved Tadalafil (TDL) for the treatment of benign prostatic hyperplasia (BPH- associated symptoms.) Pumpkin seed oil (PSO) has shown promising results for the relief of prostatitis-related lower urinary tract symptoms [111] aimed to improve the TDL with a PSO-based formula in the management of BPH. PSO, tween 80, and PEG 200 were selected for the optimization of the self nanoemulsified drug delivery system (SNEDDS). SNEDDSs are isotopic mixtures of oil, surfactants, and co-surfactant components that spontaneously form emulsions in the gastrointestinal tract (GIT) fluids. Following dilution, nanoemulsion droplets with sizes less than $20 \mathrm{~nm}$ (with $200 \mathrm{~nm}$ being the upper limit) are formed. A rat in-vivo study was carried out to investigate the prostate weight and index, histopathology, and pharmacokinetics. The average globule size was $204.8 \pm 18.76 \mathrm{~nm}$, the zeta potential was $7.86 \pm 1.21 \mathrm{mV}$. the formulation resulted in a decrease in prostate weight by $35.51 \%$ and prostate index by $36.71 \%$ compared to the testosterone-only group. Also, pharmacokinetic data revealed a 2.3-fold increase of TDL concentration from an optimized formulation in the prostate as compared to the raw TDL group. The study indicated that the combined effect of TDL and PSO in an optimized TDL-PSO SNEDDS formulation improved the efficacy of TDL in the treatment and management of BPH ( $\triangleright$ Table 1 ).

\section{Curcumin and Etoposide}

In their investigation [112], encapsulated ETP and CURinnanoemulsion and has been investigated for their effect on cancer. ETP is a well-established chemotherapeutic agent and CUR induces apoptosis in both PC-3 cells [113] and DU-145 cells [114].

The Encapsulation efficiency of ETP \& CUR was found to be $(490 \pm 11.5 \mathrm{ng} / \mathrm{ml})(98 \pm 2.3 \%$ and $1480 \pm 11.5 \mathrm{ng} / \mathrm{ml}) 99 \pm 1.7 \%$ respectively. The in-vitro drug release profile showed biphasic release behavior with an initial burst effect followed by sustained release. The particle size was less than $500 \mathrm{~nm}$. Pharmacokinetics of CUR and ETP was not affected significantly either separately or in combination. However, F5 formulation resulted in a dramatic increase in AUC of both CUR \& ETP and the trough concentration of both the drugs was higher than that of their native form of ETP \& CUR. This resulted that nanoemulsion improved absorption of both CUR \& ETP. Nanoemulsion containing solubilized hydrophobic drugs ETP \& CUR allowed for efficient intracellular delivery. In their study, they have not found any synergistic effect of CUR \& ETP against prostate cancer cells, and an instead lower degree of antagonism of CUR \& ETP was observed. Also, the degree of antagonism of ETP \& CUR was different for DU- 145 cell lines. They attributed the aberrant response of DU-145 to its inherent differences from PC-3 cells. The developed nanoemulsion could enhance the bio-availability of both CUR \& ETP. The formulation increased the response of CUR \& ETP 
significantly in both cell lines. They assumed that the antagonistic effect of ETP and CUR which was more prominent in the case of the plain drug was somehow subdued by enhanced bio-availability imparted by formulation ( $\triangleright$ Table $\mathbf{1}$ ).

\section{Babassu oil (BBS) and Copaiba oil (COP) resin}

The use of copaiba-oil resin (COP) and babassu oil (BBS) and incorporated into self-emulsifying drug delivery systems (SEDDS) [115]. The physical characteristics of the resulting nanoemulsion were next analyzed to identify the preparation suitable for in-vitro toxicity and in-vivo tests. The two most promising formulations containing BBS and with and without COP were thermodynamically stable with a zeta potential less than $-20 \mathrm{mV}$ and droplet size around $30 \mathrm{~nm}$. These formulations in the rat model of $\mathrm{BPH}$ showed promising potential to reduce the onset of this process. The SEDDS formulation developed served as an alternative incorporating BBS and COP for the treatment and prevention of BPH. The accumulation of SEDDS in hyperplastic tissues, which is a characteristic of other herbal medicine. At the same time, the synergistic effect of two oils in the association was detected, since no protective activity was observed for the use of copaiba oil alone its BBS improved outcomes ( $\vee$ Table 1). Also, the droplet size and zeta-potential suggested that SEDDS formulation would be suitable for oral administration. Altogether, these highlighted the promising potential to use phytochemicals in a SEDDS formula for control of BPH.

\section{Future Perspectives}

Nanoemulsions are used as a targeted drug delivery system in various cancer therapeutics and act as a carrier system for many anticancersbecause of their nano-meter-oil droplet size and ability to cross inside leaky tumor vasculatures. Many therapeutic agents are effective against prostate cancer but their nanoemulsionis not yet made. Hence, a nanoemulsion formulation of these drugs could be a possible treatment regimen for different types of cancer including prostate.

Different types of drugs include Lycorine which is already revealed that lycorine leads to apoptosis \& anti-proliferation in several prostate cancer cell lines. A mannosylated lipid nanoemulsion formulation loaded with lycorine-oleic complexwas prepared and assessed on the A549 cell line [116]. Thelipophilicity of lycorine was greatly enhanced which resulted in high encapsulation efficiency of the particular formulation.

Resveratrol is also a potent therapeutic in prostate cancer cell death. A resveratrol nanoemulsion was made for reducing nicotine toxicity in the lungs of rats [117]. The protective effects were seen. So, resveratrol incorporation in nanoemulsion for prostate cancer therapy will provide use in clinical applications.

Flutamideis a non-steroidal antiandrogenic poorly water-soluble drug and binds to the androgen receptor in the prostate gland. Flutamide is practically insoluble in water $(9.45 \mathrm{mg} / \mathrm{L})$; $\log \mathrm{P}(2.6)$. thus this type of nano-based system incorporating flutamide in nanoemulsion will be a good treatment in near future [118].

Thalidomide is a drug that is highly potent in many cancers such as myeloma, pancreatic, prostate, and lung. It actuates angiogenesis and advances apoptosis. Its incorporation into nanoemulsion through suitable emulsifiers can be a powerful treatment of cancers including prostate $[119,120]$.

\section{Acknowledgement}

Authors are very thankful to Research and Development department, Integral University Lucknow for providing the necessary facilities required for successful completion of this review work (IU/ R\&D/2021-MCN0001060).

\section{Conflict of Interest}

The authors declare that they have no conflicts of interest.

\section{References}

[1] Golban R. Immunology and immunopathology. Lecture course, Chisinau, uasm. Moodle. md, UASM 2015; 4: 155. p

[2] Ferlay ], Colombet M, Soerjomataram I et al. Estimating the global cancer incidence and mortality in 2018: GLOBOCAN sources and methods. Int J Cancer 2018; 144: 1941-1953

[3] Kattumuri V, Katti K, Bhaskaran S et al. Gum arabic as a phytochemical construct for the stabilization of gold nanoparticles: in vivo pharmacokinetics and X-ray-contrast-imaging studies. Small. 2007; 3: 333-341

[4] Kapoor DK, Bansal A, Sharma R et al. Advanced nanomedicine: Present contributions and future expectations. American J Phytomed Clin Therapeutics 2013; 1: 124-139

[5] Shukla R, Nune SK, Chanda N et al. Soybeans as a phytochemical reservoir for the production and stabilization of biocompatible gold nanoparticles. Small. 2008; 4: 1425-1436

[6] Sikora A, Bartczak D, Geißler D et al. A systematic comparison of different techniques to determine the zeta potential of silica nanoparticles in biological medium. Analytical Methods 2015; 7: 9835-9843

[7] Golubnitschaja O, Sridhar KC. Liver metastatic disease: new concepts and biomarker panels to improve individual outcomes. Clinical \& Experimental Metastasis 2016; 33: 743-755

[8] Golubnitschaja O. Feeling cold and other underestimated symptoms in breast cancer: Anecdotes or individual profiles for advanced patient stratification? EPMA Journal 2017; 8: 17-22

[9] Zubor P, Gondova A, Polivka J et al. Breast cancer and Flammer syndrome: Any symptoms in common for prediction, prevention and personalised medical approach? EPMA Journal 2017; 8: 129-140

[10] Fröhlich H, Patjoshi S, Yeghiazaryan K et al. Premenopausal breast cancer: potential clinical utility of a multi-omics based machine learning approach for patient stratification. EPMA Journal 2018; 9: 175-186

[11] Zubor P, Kubatka P, Dankova Z et al. miRNA in a multiomic context for diagnosis, treatment monitoring and personalized management of metastatic breast cancer. Future Oncology 2018; 14: 1847-1867

[12] "Prostate Cancer". National Cancer Institute. January 1980. Archived from the original on 12 October 2014. Retrieved 12 October 2014.

[13] "Chapter 5.11". World Cancer Report. World Health Organization. 2014. ISBN 978-9283204299

[14] "Chapter 1.1". World Cancer Report. World Health Organization. 2014. ISBN 978-9283204299 
[15] Bray F, Ferlay J, Soerjomataram I et al. Global cancer statistics 2018: GLOBOCAN estimates of incidence and mortality worldwide for 36 cancers in 185 countries. CA: A cancer journal for clinicians. 2018; 68: 394-424 doi:10.3322/caac.21492

[16] Baade PD, Youlden DR, Krnjacki LJ. International epidemiology of prostate cancer: Geographical distribution and secular trends. Molecular Nutrition \& Food Research 2009; 53: 171-184. doi:10.1002/mnfr.200700511 PMID 19101947

[17] Siegel R, Naishadham D, Jemal A. Cancer statistics, 2013. CA Cancer J Clin 63: 11-30 2013

[18] "Prostate Cancer Statistics". Laparoscopic Urology. Archived from the originalon 24 June 2016. Retrieved 19 June 2016

[19] Overview: Prostate Cancer - What Causes Prostate Cancer? Archived2006-04-04 at the Wayback Machine American Cancer Society (2 May 2006). Retrieved on 5 April 2007

[20] Prostate Cancer FAQs. Archived 2006-05-29 at the Wayback MachineState University of New York School of Medicine Department of Urology (31 August 2006). Retrieved on 5 April 200

[21] Rendon RA, Mason RJ, Marzouk K et al. Canadian Urological Association recommendations on prostate cancer screening and early diagnosis. Canadian Urological Association Journal 2017; 11: 298-310. doi:10.5489/cuaj.4888 PMC 5659858. PMID 29381452

[22] "Prostate cancer statistics". Cancer Research UK. Archived from the original on 6 October 2014. Retrieved 3 October 2014

[23] Ferlay JEM, Lam F, Colombet M et al. Global cancer observatory: cancer tomorrow.Lyon, France: International Agency for Research on Cancer; Available from: https://gco.iarc.fr/tomorrow, Accessed 02 February 2019

[24] Huggins C, Hodges CV. Studies on prostatic cancer. I. The effect of castration, of estrogen and androgen injection on serum phosphatases in metastatic carcinoma of the prostate. CA Cancer J Clin 1972; 22: 232-240

[25] Kirby M, Hirst C, Crawford ED. Characterising the castration, resistant prostate cancer population: a systematic review. International journal of Clinical Practice 2011; 65: 1180-1192

[26] Siegel R, Ma J, Zou Z et al. Cancer statistics, 2014. CA Cancer J Clin 2014; 64: 9-29

[27] Ferlay J, Steliarova-Foucher E, Lortet-Tieulent J et al. Cancer incidence and mortality patterns in Europe: estimates for 40 countries in 2012 Eur J Cancer 2013; 49: 1374-1403

[28] Bostwick DG, Burke HB, Djakiew D et al. Human prostate cancer risk factors. Cancer 2004; 101: 2371-2490

[29] Dagnelie PC, Schuurman AG, Goldbohm RA et al. Diet, anthropometric measures and prostate cancer risk: a review of prospective cohort and intervention studies. BJU Int 2004; 93: 1139-1150

[30] Pienta KJ, Esper PS. Risk factors for prostate cancer. Ann Intern Med 1993; 118: 793-803

[31] Rybak AP, Bristow RG, Kapoor A. 2015; Prostate cancer stem cells: deciphering the origins and pathways involved in prostate tumorigenesis and aggression. Oncotarget 6: p 1900

[32] "Prostate Cancer Treatment (PDQ) - Patient Version". National Cancer Institute. 2014-04-08. Archived from the original on 5 July 2014. Retrieved 1 July 2014.

[33] Anand P, Kunnumakkara AB, Newman RA et al. Bioavailability of curcumin: problems and promises. Molecular Pharmaceutics 2007; Dec 3 4: 807-818

[34] Sharma RA, Steward WP, Gescher AJ. Pharmacokinetics and pharmacodynamics of curcumin.In The molecular targets and therapeutic uses of curcumin in health and disease. 2007: pp. 453-470 Springer; Boston, MA:
[35] Shaikh J, Ankola DD, Beniwal V et al. Nanoparticle encapsulation improves oral bioavailability of curcumin by at least 9 -fold when compared to curcumin administered with piperine as absorption enhancer. European Journal of Pharmaceutical Sciences 2009; 37: 223-230

[36] Moorthi C, Krishnan K, Manavalan R et al. Preparation and characterization of curcumin-piperine dual drug loaded nanoparticles. Asian Pacific Journal of Tropical Biomedicine 2012; 2: 841-848

[37] Yu H, Li J, Shi K et al. Structure of modified $\varepsilon$-polylysine micelles and their application in improving cellular antioxidant activity of curcuminoids. Food \& Function 2011; 2: 373-380

[38] Yu H, Huang Q. Improving the oral bioavailability of curcumin using novel organogel-based nanoemulsions. Journal of Agricultural and Food Chemistry 2012; 60: 5373-5379

[39] Méndez FB, Medrano FJ, Pariona $\mathrm{N}$ et al. Recent Progress in Antitumoral Nanotechnology. Int J Nanoparticles Nanotech 2015; 1 : 2-10

[40] Nishiyama N, Kataoka K. Current state, achievements, and future prospects of polymeric micelles as nanocarriers for drug and gene delivery. Pharmacology \& Therapeutics 2006; 112: 630-648

[41] Torchilin VP. Micellar nanocarriers: pharmaceutical perspectives. Pharmaceutical Research 2007; 24: 1

[42] Mulik RS, Mönkkönen J, Juvonen RO et al. Transferrin mediated solid lipid nanoparticles containing curcumin: enhanced in vitro anticancer activity by induction of apoptosis. International Journal of Pharmaceutics 2010; 398: 190-203

[43] Anat EB, Keren M, Joaquin S et al. Biomater 32: 2011; 3862-3874

[44] Danhier F, Vroman B, Lecouturier $\mathrm{N}$ et al. Targeting of tumor endothelium by RGD-grafted PLGA-nanoparticles loaded with paclitaxel. Journal of Controlled Release 2009; 140: 166-173

[45] Ganta S, Paxton JW, Baguley BC et al. Pharmacokinetics and pharmacodynamics of chlorambucil delivered in parenteral emulsion. Int J Pharm 2008; 360: 115-121

[46] Ganta S, Sharma P, Paxton JW et al. Pharmacokinetics and pharmacodynamics of chlorambucil delivered in long-circulating nanoemulsion. Journal of Drug Targeting 2010; 18: 125-133

[47] Talekar M, Ganta S, Singh A et al. Phosphatidylinositol 3-kinase inhibitor (PIK75) containing surface functionalized nanoemulsion for enhanced drug delivery, cytotoxicity and pro-apoptotic activity in ovarian cancer cells. Pharm Res 2012; 29: 2874-2886

[48] Patlolla RR, Vobalaboina V. Pharmacokinetics and tissue distribution of etoposide delivered in parenteral emulsion. J Pharm Sci 2005; 94: 437-445

[49] Tiwari S, Tan YM, Amiji M. Preparation and in vitro characterization of multifunctional nanoemulsions for simultaneous MR imaging and targeted drug delivery. Journal of Biomedical Nanotechnology 2006; 2: $217-224$

[50] Gianella A, Jarzyna PA, Mani V et al. Multifunctional nanoemulsion platform for imaging guided therapy evaluated in experimental cancer. ACS Nano 2011; 5: 4422-4433

[51] Gupta S, Kesarla R, Omri A. Formulation strategies to improve the bioavailability of poorly absorbed drugs with special emphasis on self-emulsifying systems. ISRN Pharm 2013; 2013: 848043

[52] Rahman A, Harwansh R, Mirza A et al. Oral lipid based drug delivery system: formulation, characterization and application: a review. Curr Drug Deliv 2011; 8: 330-345

[53] Jemal A, Bray F, Center MM et al. Global cancer statistics. CA Cancer J. Clin 2011; 61: 69-90

[54] Reya T, Morrison SJ, Clarke MF et al. Stem cells, cancer, and cancer stem cells. Nat. Cell Boil 2001; 414: 105-111 
[55] Murali R, Varghese BA, Nair R et al. The role of cancer stem cells in tumor heterogeneity and resistance to therapy. Can. J. Physiol. Pharmacol. 2017; 95: 1-15

[56] Ahmad G, Sadda El, Botchkina R et al. Formulation of a Novel Taxoid DHA-SBT-1214 Inhibits Prostate Cancer Stem Cell-Induced Tumor Growth. Cancer Lett 2017; 406: 71-80

[57] Gillet J-P, Calcagno AM, Varma S et al. Redefining the relevance of established cancer cell lines to the study of mechanisms of clinical anti-cancer drug resistance. Proc Natl Acad Sci USA 2011; 108: 18708-18713

[58] McClements D], Rao J. Food-grade nanoemulsions: formulation, fabrication, properties, performance, biological fate, and potential toxicity. Critical Reviews in Food Science and Nutrition 2011; 51: 285-330

[59] Salvia-Trujillo L, Rojas-Graü MA, Soliva-Fortuny R et al. Use of antimicrobial nanoemulsions as edible coatings: Impact on safety and quality attributes of fresh-cut Fuji apples. Postharvest Biology and Technology 2015; 105: 8-16

[60] Tadros T, Izquierdo R, Esquena J et al. 2004; Formation and stability of nano-emulsions. Advances in Colloid and Interface Science 108-109: 303-318

[61] Wooster T, Golding M, Sanguansri P. 2008; Impact of oil type on nanoemulsion formation and Ostwald ripening stability. Langmuir 24: $12758-12765$

[62] McClements D]. Nanoemulsions versus microemulsions: terminology, differences and similarities. Soft Matter 2012; 8: 1719-1729

[63] Ganta S, Talekar M, Singh A et al. Nanoemulsions in Translational Research-Opportunities and Challenges in Targeted Cancer Therapy. AAPS PharmSciTech 2014; 15: 694-708

[64] Gi HJ, Chen SN, Hwang JS et al. Studies of Formation and Interface of Oil-Water Microemulsion. Chin. J. Phys 1992; 30: 665-678

[65] Devarajan V, Ravichandran V. Nanoemulsions: As modified drug delivery tool. Pharm. Glob 2011; 2: 1-6

[66] Kale SN, Deore SL. Emulsion micro emulsion and nano emulsion: A review. Syst Rev Pharm 2016; 8: 39-47

[67] Danhier F, Feron O, Préat V. To exploit the tumor microenvironment: Passive and active tumor targeting of nanocarriers for anti-cancer drug delivery. J Control Release 2010; 148: 135-146

[68] Qadir A, Faiyazuddin M, Hussain MT et al. Critical steps and energetics involved in a successful development of a stable nanoemulsion. J Mol Liq 2016; 214: 7-18

[69] Amin N, Das B. A Review on Formulation and Characterization of Nanoemulsion. Int J Curr Pharm Res 2019; 11: 42-46

[70] Yuliani S, Noveriza R. Effect of carrier oil and co-solvent on the formation of clove oil nanoemulsion by phase inversion technique. IOP Conf. Ser. Earth Environ Sci. 2019; 309

[71] Ganta S, Talekar M, Singh A et al. Nanoemulsions in Translational Research-Opportunities and Challenges in Targeted Cancer Therapy. AAPS PharmSciTech 2014; 15: 694-708

[72] Gupta A, Burak HE, Hatton TA et al. Nanoemulsions: formation, properties and applications. Soft Matter 2016; 12: 2826e41

[73] Bae YH. Drug targeting and tumor heterogeneity. J Control Release 2009; 133: 2-3

[74] Peer D, Karp JM, Hong $S$ et al. Nanocarriers as an emerging platform for cancer therapy. Nat Nanotechnol 2007; 2: 751-760

[75] Hedeman M, Brøndsted H, Müllertz A et al. Fat emulsions based on structured lipids (1, 3-specific triglycerides): an investigation of the in vivo fate. Pharmaceutical Research 1996; May 1 13: 725-728

[76] Haider MF, Khan S, Gaba B et al. Optimization of rivastigmine nanoemulsion for enhanced brain delivery: in-vivo and toxicity evaluation. J Molecular Liquids 2018; 255: 384-396
[77] Tiwari S, Tan Y-M, Amiji M. Preparation and in vitro characterization of multifunctional nanoemulsions for simultaneous MR imaging and targeted drug delivery. J Biomed Nanotechnol 2006; 2: 3-4

[78] Gallarate M, Chirio D, Bussano R et al. Development of O/W nanoemulsions for ophthalmic administration of timolol. Int J Pharm 2013; 440: 126-134. 15

[79] Nesamony J, Shah IS, Kalra A et al. Nebulized oil-in-water nanoemulsion mists for pulmonary delivery: development, physico-chemical characterization and in vitro evaluation. Drug Dev Ind Pharm. 2013; 40: $1253-1263$

[80] Khandavilli S, Panchagnula R. Nanoemulsions as versatile formulations for paclitaxel delivery: peroral and dermal delivery studies in rats. J Investig Dermatol 2007; 127: 154-162

[81] Jaiswal M, Dudhe R, Sharma PK. Nanoemulsion: An advanced mode of drug delivery system. 3 Biotech 2015; 5: 123-127

[82] Ahmad U, Akhtar J, Singh SP et al. Silmayrinnanoemulsion against human hepatocellular carcinoma: development and optimization. Artificial Cells, Nanomedicine, and Biotechnology 2018; 46: 231-241

[83] Chaudhry Q, Scotter M, Blackburn J et al. Applications and implications of nanotechnologies for the food sector. Food additives and contaminants 2008; $25: 241-258$

[84] Jiang, J, G et al. 2009; Characterization of size, surface " charge, and agglomeration state of nanoparticle dispersions for toxicological studies. Journal of Nanoparticle Research 11: 77-89

[85] Dube A, Nicolazzo JA, Larson I. Chitosan nanoparticles enhance the intestinal absorption of the green tea catechins (+)-catechin and (-)-epigallocatechin gallate. Eur J Pharm Sci 2010; 41: 219-225

[86] Kale A, Gawande S, Kotwal S et al. Studies on the effects of oral administration of nutrient mixture, quercetin and red onions on the bioavailability of epigallocatechin gallate from green tea extract. Phytother Res 2010; 24: 48-55

[87] Lante A, Friso D. Oxidative stability and rheological properties of nanoemulsion with ultrasonic extracted green tea infusion. Food Res Int 2013; 54: 269-276

[88] Kim Y], Houng S], Kim JH et al. Nanoemulsified green tea extract shows improved hypocholesterolemic effects in C57BL/6 mice. J NutrBiochem 2012; 23: 186-191

[89] Tsai Y], Chen BH. Preparation of catechin extracts and nanoemulsions from green tea leaf waste and their inhibition effect on prostate cancer cell PC-3. International Journal of Nanomedicine 2016; 11: 1907

[90] Khan N, Afaq F, Saleem M et al. Targeting multiple signaling pathways by green tea polyphenol (-)-epigallocatechin-3-gallate. Cancer Res 2006; 66: 2500-2505

[91] Sun J, Bi C, Chan HM et al. Curcumin-loaded solid lipid nanoparticles have prolonged in vitro antitumour activity, cellular uptake and improved in vivo bioavailability. Colloids Surf B Biointerfaces 2013; 111: 367-375

[92] Bisht S, Feldmann G, Soni S et al. Polymeric nanoparticle-encapsulated curcumin ("nanocurcumin"): a novel strategy for human cancer therapy. J Nanobiotechnol 2007; 5: 3-10

[93] Ucisik MH, Küpcü S, Schuster B et al. Characterization of CurcuEmulsomes: nanoformulation for enhanced solubility and delivery of curcumin. J Nanobiotechnol 2013; 11: 11-37

[94] Guan YB, Zhou SY, Zhang YQ et al. Therapeutic effects of curcumin nanoemulsions on prostate cancer. Journal of Huazhong University of Science and Technology [Medical Sciences] 2017; 37: 371-378

[95] Teiten MH, Gaascht F, Eifes S et al. Chemopreventive potential of curcumin in prostate cancer. Genes \& Nutrition 2010; 5: 61-74

[96] Chrastina A, Baron VT, Abedinpour P et al. Plumbagin-loaded nanoemulsion drug delivery formulation and evaluation of antiproliferative effect on prostate cancer cells. BioMed Research International. 2018; 11: 2018 
[97] Panichayupakaranant P, Ahmad MI. Plumbagin and its role in chronic diseases. In: Drug Discovery from Mother Nature. 2016: pp. 229-246 Springer; Cham

[98] Ahmad M, Sahabjada JA, Hussain A et al. Development of a new rutinnanoemulsion and its application on prostate carcinoma PC3 cell line. Excli Journal 2017; 16: 810

[99] Goldstein D, Gofrit O, Nyska A et al. Anti-HER2 cationic immunoemulsion as a potential targeted drug delivery system for the treatment of prostate cancer. Cancer Research 2007; 67: 269-275

[100] Castilla C, Flores ML, Medina R et al. Prostate cancer cell response to paclitaxel is affected by abnormally expressed securin PTTG1. Molecular Cancer Therapeutics 2014; 13: 2372-2383

[101] Cockshott ID, Oliver SD, Young J] et al. The effect of food on the pharmacokinetics of the bicalutamide ('Casodex') enantiomers. Biopharm. Drug Dispos. 1997; 18: 499-507

[102] Fradet Y. Bicalutamide (Casodex) in the treatment of prostate cancer. Expert Rev. Anticancer Ther 2004; 4: 37-48

[103] Schellhammer PF, Davis JW. An evaluation of bicalutamide in the treatment of prostate cancer. Clin. Prostate Cancer 2004; 2: 213-219

[104] Takegami S, Uchida S, Aoi E et al. Effect of bovine serum albumin on the stability of bicalutamide-encapsulated lipid nano-emulsion in bovine serum. Current Nanoscience 2012; 8: 187-192

[105] Floyd MS, Teahan SJ, Fitzpatrick JM et al. Differential mechanisms of bicalutamide-induced apoptosis in prostate cell lines. Prostate Cancer and Prostatic Diseases 2009; Mar 12: 25-33

[106] Ali MS, Alam MS, Alam N et al. Preparation, characterization and stability study of dutasteride loaded nanoemulsion for treatment of benign prostatic hypertrophy. Iranian Journal of Pharmaceutical Research: IJPR 2014; 13: 1125

[107] Schmidt LJ, Murillo H, Tindall DJ. Gene expression in prostate cancer cells treated with the dual 5 alpha-reductase inhibitor dutasteride. Journal of Andrology 2004; 25: 944-953

[108] Chourasia Mk, Khan Fa. Docetaxel Nanoemulsion For Effective Chemotherapy of Prostate Cancer (Doctoral dissertation).

[109] Yang C, Zhang W, Wang J et al. Effect of docetaxel on the regulation of proliferation and apoptosis of human prostate cancer cells. Molecular Medicine Reports 2019; 19: 3864-3870

[110] Komura K, Jeong SH, Hinohara K et al. Resistance to docetaxel in prostate cancer is associated with androgen receptor activation and loss of KDM5D expression. Proceedings of the National Academy of Sciences 2016; 113: 6259-6264
[111] Alhakamy NA, Fahmy UA, Ahmed OA. Attenuation of Benign Prostatic Hyperplasia by Optimized Tadalafil Loaded Pumpkin Seed Oil-Based Self Nanoemulsion: In Vitro and In Vivo Evaluation. Pharmaceutics. 2019; 11: 640

[112] Shukla P, Mathur V, Kumar A et al. Nanoemulsion based concomitant delivery of curcumin and etoposide: Impact on cross talk between prostate cancer cells and osteoblast during metastasis. Journal of Biomedical Nanotechnology 2014; 10: 3381-3391

[113] Hilchie AL, Furlong S], Sutton K et al. Curcumin-induced apoptosis in PC3 prostate carcinoma cells is caspase-independent and involves cellular ceramide accumulation and damage to mitochondria. Nutrition and cancer 2010; 62: 379-389

[114] Mukhopadhyay A, Bueso-Ramos C, Chatterjee D et al. Curcumin downregulates cell survival mechanisms in human prostate cancer cell lines. Oncogene. 2001; 20: 7597-7609

[115] de Abreu LC, de Souza Furtado P, da Silva Honorio T et al. A synergistic nanoformulation of babassu and copaiba oils as natural alternative for prevention of benign prostatic hyperplasia. Journal of Drug Delivery Science and Technology 2018; 47: 167-175

[116] Guo Y, Liu X, Sun X et al. Mannosylated lipid nano-emulsions loaded with lycorine-oleic acid ionic complex for tumor cell-specific delivery. Theranostics. 2012; 2: 1104

[117] Mohamed FT, Abdelghfour AY, Morsy BA et al. Promising inhibitor against mitogen-activated protein kinase-dependent inflammation and ameliorates nicotine induced-lung toxicity in rats. Free Radicals and Antioxidants 2020; 10: 35-41

[118] Pouton CW. Lipid formulations for oral administration of drugs: non-emulsifying, self-emulsifying and 'self-microemulsifying'drug delivery systems. European Journal of Pharmaceutical Sciences 2000; 11: $593-598$

[119] Kushwaha RS, Chasta P, Ahmed A et al. A Novel Approach on Thalidomide and their Analogues with their Therapeutic uses and Clinical Application. IJTSRD 2019; 3: 1022-1036

[120] Khuroo T, Verma D, Talegaonkar $S$ et al. Topotecan tamoxifen duple PLGA polymeric nanoparticles: Investigation of in vitro, in vivo and cellular uptake potential. Int J Pharmaceutics 2014; 473: 384-394 